Media Komunikasi dan Informasi Hukum dan Masyarakat

Volume : 20, Nomor : 1

ISSN Online : 2613-9340

ISSN Offline : 1412-1255

\section{Arah Kebijakan Pemerintah Terhadap Pekerja Asing Di Indonesia}

\author{
Oleh : \\ Jauhari Ginting ${ }^{1}$ \\ jgkemkem@gmail.com
}

\begin{abstract}
Employment is a very vital thing in human life. All humans realize the importance of having and doing work for themselves and their families, in supporting their daily needs in their lives. Those needs can be fulfilled if the human does the job. In the current era of globalization, with the development of industry and investment that involves the international world is increasingly growing, the world of Indonesian manpower is also moving. In order to boost the development of Indonesian industry, in the world of manpower, Indonesia requires skilled workers (experts) to sustain the operation of the industries in question. Experts from Indonesian workers are still very limited (lacking) and still need guidance. Filling the vacancy, foreign workers (TKA) are used to sustain it. The placement of foreign workers in Indonesia in filling the vacancy is temporary. The Indonesian government must have a clear policy direction regarding the presence of foreign workers in Indonesia. The placement of foreign workers must receive benefits (added value) for the state and nation of Indonesia, especially for the Indonesian workers themselves.
\end{abstract}

\section{Keyword : Direction Of Government, Policy Towards Foreign Workers, Indonesia}

\section{Abstrak}

Ketenagakerjaan merupakan hal sangat vital dalam kehidupan manusia. Semua manusia menyadari pentingnya mempunyai dan melakukan pekerjaan untuk dirinya dan keluarganya, dalam menopang kebutuhan sehari-hari mengharungi hidup dan kehidupannya. Kebutuhan itu dapat dipenuhi jika manusia itu melakukan pekerjaan. Pada masa globalisasi saat ini, dengan perkembangan pembangunan industri dan investasi yang semakin berkembang melibatkan dunia internasional, dunia Ketenagakerjaan Indonesia, juga ikut bergerak. Untuk

\footnotetext{
${ }^{1}$ Dosen
}

mendongkrak perkembangan industri Indonesia tersebut, dalam dunia ketenagakerjaan Indonesia membutuhkan pekerja-pekerja ahli (tenaga-tenaga ahli) untuk menopang pengoperasian industri-industri yang dimaksud. Tenaga ahli dari Pekerja Indonesia masih sangat terbatas (kurang) dan masih perlu pembinaan. Mengisi kekosongan tersebut, maka dipergunakan Tenaga Kerja Asing (TKA) untuk menopangnya. Penempatan TKA di Indonesia dalam mengisi kekosongan tersebut adalah bersifat sementara. Pemerintah Indonesia harus mempunyai arah kebijakan yang jelas tentang keberadaan TKA itu di Indonesia. Penempatan TKA tersebut haruslah mendapat keuntungan (nilai lebih) bagi negara dan bangsa Indonesia khususnya terhadap pekerja-pekerja Indonesia itu sendiri.

Kata Kunci : Arah Kebijakan, Pemerintah, Terhadap Kerja Asing

\section{Pendahuluan}

\section{A. Latar Belakang}

Negara Indonesia sebagai suatu Negara yang sedang giat-giatnya melaksanakan pembangunan, terutama pembangunan dibidang industri, yang jangkauannya masih sangat luas di Indonesia membutuhkan banyak teknologi dan banyak tenaga-tenaga ahli dibidang tertentu. Sumber daya Pekerja Indonesia dibidang keahlian tertentu, masih terbatas, masih perlu banyak belajar dari tenaga kerjai negara lain, yang sudah terlebih dahulu berkembang bidang keilmuan dan teknologinya.

Negara harus melirik peraturan hukum tentang Tenaga Kerja Negara lain atau Tenaga Kerja Asing (TKA) sesuai dengan yang dibutuhkan oleh perusahaan-perusahaan di Indonesia yang sedang berkembang.

Pengoperasian awal dan maintenance (perawatan mesin-mesin), maka Negara tersebut mengirim juga tenaga kerjanya, biasanya sekaligus satu paket dengan barang teknologi negara yang bersangkutan sesuai dengan perjanjian yang disepakati. 
Media Komunikasi dan Informasi Hukum dan Masyarakat

Perkembangan investasi asing di Indonesia, khususnya investasi dibidang industry seperti pendirian mesin- mesin dan pabrik-pabrik, Negara yang memberi investasi biasanya mempersyaratkan bahwa tenaga kerja ahlinya harus berasal dari Negara yang bersangkutan. Negara penerima (Indonesia) sangat berkepentingan untuk keahlian mereka dapat ditularkan kepada para Pekerja Indonesia, sehingga pada masa yang akan datang negara Indonesia tidak sangat tergantung dari keahlian TKA .

Masuknya TKA ke Indonesia, mempunyai dampak positif dan negatif dari kepada bangsa Indonesia. Misalnya terhadap aspek budaya, pendidikan, politik, ekonomi pertahanan keamanan dan lain-lain. Perhatian khusus harus diberikan kepada tenaga kerja/pekerja Indonesia (TKI) agar tetap mendapat perlindungan, kenyamanan pekerjaan/ kesejahteraan, tidak menjadikannya menjadi pengangguran di Negara sendiri. Pengusaha dapat mengembangkan usahanya dengan sebaik- baiknya.

Daryati dan Agus Budianto menyatakan:

Pemerintah berkewajiban untuk memberikan perlindungan kepada tenaga kerja dan pengusaha, dengan tujuan agar pekerja dan pengusaha terlindungi, sehingga pengusaha dapat mengembangkan sahamnya, menciptakan lapangan pekerjaan serta mengatasi pengangguran, dan pekerja dapat mengembangkan keahlian yang dimilikinya. Pengusaha tanpa pekerja tidak akan dapat melanjutkan usahanya, berapapun besarnya modal yang dimiliki, sebaliknya pekerja tidak akan dapat mempergunakan ilmunya yang hebat tanpa ada pengusaha yang membuka lapangan pekerjaan. Hubungan kerja antara pekerja dengan pengusaha saling membutuhkan. $^{2}$

Selanjutnya menurut pendapat Prof. John Ruggie bahwa perusahaan mempunyai tanggungjawab untuk menghormati/ tidak melanggar hak orang lain. Standar ini secara sederhana berarti, kegiatan-kegiatan yang dilakukan oleh perusahaan harus mempertimbangkan dampak negatif yang dapat diakibatkan bagi orang lain, termasuk melalui hubungan-hubungan perusahaan, dan mengambil tindakan yang cukup untuk menghindari dampak negatif tersebut." ${ }^{3}$

Perkembangan pergaulan internasional, dimana alat komunikasi dan transportasi yang semakin maju, mendukung semakin mudahnya pergaulan tersebut terlaksana. Terjadi migrasi penduduk, demikian juga dengan penanaman investasi dari negara-negara lain, yang akan membutuhkan pengawasan secara langsung dari investor, melalui penempatan pekerjanya didalam perusahaan tersebut.

Dalam rangka penyelenggaraan perekonomian nasional, dalam upaya untuk meningkatkan pertumbuhan ekonomi, menciptakan lapangan pekerjaan, dan meningkatkan pembangunan ekonomi berkelanjutan, maka Pemerintah Indonesia berupaya agar iklim investasi dapat berkembang di Indonesia, dapat dilihat dari upaya

${ }^{2}$ Darwati dan Azis Budianto, Analisa Hukum Perjanjian Kerja waktu tertentu berdasarkan Undangundang No. 13 Tahun 2003 tentang Ketenagakerjaan (Studi kasus Putusan PHI No. 46/PHI.G/2013/PN.Jkt.PST), Lex Publica (Jurnal ilmu hukum Asosiasi Pimpinan Perguruan Tinggi Hukum Indonesia) Volume IV nomor 1, Penerbit Asosiasi Pimpinan Perguruan Tinggi Hukum Indonesia, Jakarta, 2017, hal. 688.

3.John Ruggie, Bagaimana menjalankan bisnis dengan menghormati hak asasi manusia, Global Compact Network Indonesia, Lembaga Studi dan Advokasi Masyarakat (ELSAM), Jakarta, hal. 12. 
Media Komunikasi dan Informasi Hukum dan Masyarakat

Pemerintah terus mempromosikan dan menawarkan berbagai produk investasi Indonesia pada pihak asing. ${ }^{4}$

Dalam keimigrasian Keimigrasian, para pelaku penanaman modal asing diberikan kesempatan untuk menggunakan tenaga kerja asing dengan kemudahan perizinan keimigrasian. ${ }^{5}$

Jadi pada kenyataannya Indonesia masih sangat membutuhkan masuknya investasi asing, maka Indonesia juga harus membuka diri untuk menerima tenaga kerja (pekerja) asing di perusahaan-perusahaan yang terdapat diwilayah Indonesia.

Disisi lain sebagai suatu Negara merdeka dan berdaulat, Republik Indonesia mempunyai kepentingan untuk mengatur dan membuat kebijakan dalam penempatan TKA yang bekerja di perusahaan-perusahaan yang berada di wilayah Republik Indonesia. Penempatan Tenaga Kerja asing haruslah melalui mekanisme dan prosedur yang selektif.

Artinya masuknya tenaga kerja asing di Indonesia, disampingUndang-Undang No. 13 Tahun 2003 tentang Ketenagakerjaan harus juga memperhatikan Undang-Undang Negara Republik Indonesia No. 6 Tahun 2011 tentang Keimigrasian. Dalam pertimbangan Undangundang Keimigrasian dinyatakan:

a. Keimigrasian merupakan bagian perwujudan pelaksanaan penegakan kedaulatan atas wilayah Indonesia dalam menjaga ketertiban kehidupan berbangsa dan bernegara menuju masyarakat yang

4.Jazim Hamidi dan Charles Christian, Hukum Keimigrasian bagi orang asing di Indonesia, Sinar Grafika, Jakarta, hal. 56

5. Jazim Hamidi, Ibid, hal. 57 adil dan makmur berdasarkan Pancasila dan UUD Negara RI Tahun 1945;

b. Perkembangan global dewasa ini mendorong meningkatnya mobilitas penduduk dunia yang menimbulkan berbagai dampak, baik yang menguntungkan maupun yang merugikan kepentingan Negara dan bangsa Indonesia, sehingga diperlukan peraturan perundangundangan yang menjamin kepastian hukum yang sejalan dengan penghormatan, perlindungan dan pemajuan Hak Asasi Manusia. ${ }^{6}$

c. Pemerintah penting melakukan pengawasan terhadap warga Negara asing yang berada di wilayah Indonesia, tentang keberadaan dan kegiatan yang dilakukannya. Penggunaan TKA di Indonesia memang mempunyai dampak positif,namun tidak dapat disangkal juga mempunyai dampak negatif. Untuk meniadakan dampak atau meminimalkan dampak negatif ini, haruslah ada regulasi yang ketat, yang diiringi oleh perilaku baik dari pemangku kewenangan terhadap hal itu. Untuk itu penulis hendak mengangkatnya menjadi suatu pembahasan dalam karya ilmiah, dengan judul : Arah Kebijakan Pemerintah terhadap Tenaga Kerja Asing (TKA) di Indonesia.

\section{B. Perumusan Masalah}

Berdasarkan uraian-uraian yang telah dipaparkan di latar belakang penelitian ini, maka dapat ditarik sebuah permasalahan sebagai berikut :

1. Bagaimanakan pengaturan tenaga kerja asing di wilayah Indonesia?

${ }^{6}$.Sihar Sihombing, Hukum Keimigrasian dalam Hukum Indonesia, Nuansa Aulia, Jakarta, hal.190. 
Media Komunikasi dan Informasi Hukum dan Masyarakat

2. Bagaimanakah syarat-syarat tenaga kerja asing di Indonesia?

\section{Metode Penelitian}

Spesifikasi penelitian yang digunakan adalah bersifat deskriptif analitis. Metode pendekatan yang digunakan dalam penelitian ini adalah pendekatan yuridis normatif. Metode pendekatan yuridis normatif yaitu penelitian hukum yang dilakukan dengan mengutamakan meneliti bahan pustaka atau dokumen yang disebut data sekunder, berupa bahan-bahan hukum primer, sekunder dan tersier. Data yang diperoleh kemudian dianalisa secara kualitatif.

Analisis data yang digunakan dalam penelitian ini adalah analisis secara kualitatif yaitu uraian yang dilkukan peneliti terhadap data yang terkumpul tidak menggunakan statistik atau matematika ataupun sejenisnya tetapi berupa uraian-uraian kalimat yang tersusun secara sistematis sesuai dengan permaslahan yang dibahas dalam penelitian ini.

Dalam menarik kesimpulan penulis menggunakan metode dedukatif yaitu merupakan cara berfikir yang menarik kesimpulan dari suatu pernyataan atau dalil yang bersifat umum menjadi suatu pernyataan yang bersifat khusus.

\section{Hasil dan Penelitian}

\section{A. Pengaturan Tenaga Kerja Asing di Wilayah Indonesia}

Pengertian Tenaga Kerja Asing (TKA) menurut Undang-undang No. 13 tahun 2003, yaitu dalam pasal 1 angka 13, TKA adalah: warga Negara asing pemegang visa dengan maksud bekerja diwilayah Indonesia.

Menurut Sihar Sihombing, SH,.MH: Tenaga Kerja Asing adalah warga negara asing pemegang visa dengan maksud bekerja di wilayah Indonesia.

Menurut Abdul Rachmat Budiono, TKA adalah Setiap orang bukan warga Negara Indonesia yang mampu melakukan pekerjaan baik didalam maupun diluar hubungan kerja, guna menghasilkan jasa atau barang guna memenuhi kebutuhan masyarakat.

Dalam Peraturan Menteri Hukum dan HAM No. 24 Tahun 2016 tentang Prosedur Teknis permohonan dan pemberian Visa Kunjungan dan visa tinggal terbatas, dijelaskan bahwa Visa Tinggal terbatas terbagi dua:

a. Visa Tinggal Terbatas dalam rangka bekerja yang meliputi:

(1) bekerja sebagai tenaga ahli;

(2) untuk bekerja diatas kapal, alat apung atau instalasi yang beroperasi didaerah perairan Indonesia, laut territorial, landas kontinen, serta zona ekonomi eksklusif;

(3) Melaksanakan tugas sebagai rohaniawan;

(4) Bekerja melakukan kegiatan Profesi dengan menerima bayaran;

(5) Melakukan kegiatan dalam rangka pembuatan film yang bersifat komersial dan telah mendapat izin dari instansi yang berwenang;

(6) Bekerja melakukan pengawasan terhadap kualitas barang dan atau produksi;

(7) Melakukan audit atau inspeksi terhadap cabang Perusahaan di Indonesia; 
Media Komunikasi dan Informasi Hukum dan Masyarakat

(8) Memasang dan memperbaiki mesin; atau ke Pejabat yang ditetapkan untuk itu, Melakukan pekerjaan non permanen dengan melampirkan:

dalam rangka konstruksi;

(9) Mengadakan pertunjukan kesenian,

a. Paspor yang masih berlaku music dan olahraga;

b. Tiket keberangkatan

c. Keterangan jaminan tersedianya biaya

(10) Mengadakan kegiatan olahraga professional; hidup bagi yang bersangkutan selama berada di wilayah Indonesia.

(11) Melakukan kegiatan pengobatan;

(12) Serta kegiatan calon tenaga kerja asing yang akan bekerja dalam rangka uji coba keahlian.

d. Pas Photo dan

e. Membayar visa sesuai dengan ketentuan. Kadang-kadang permohonan visa ini ditolak terhadap WNA, dengan alasan:

a. Nama yang bersangkutan tercantum dalam daftar penangkalan;

(13) Visa Tinggal terbatas tidak dalam rangka bekerja mencakup:

b. Tidak memiliki dokumen perjalanan yang syah dan masih berlaku;

(14) Melakukan penanaman modal asing;

(15) Mengikuti pelatihan dan penelitian ilmiah;

(16) Penyatuan Keluarga yaitu 1. orang asing yang menggabungkan diri dengan suami atau istri yang warga Negara Indonesia 2. orang asing yang menggabungkan diri dengan suami/ istri pemegang izin tinggal terbatas atau izin tinggal tetap 3. anak perkawinan yang syah antara orang asing dengan warga Negara Indonesia 4. anak yang belum berusia 18 tahun dan belum kawin dari orang asing yang kawin secara syah dengan warga Negara Indonesia. 5 Anak yang belum berusia 18 tahun dan belum kawin yang menggabungkan diri dengan orang tuanya pemegang izin tinggal terbatas atau izin tetap. ${ }^{7}$

Visa diberikan didasarkan kepada permohonan calon TKA kepada kepala perwakilan Republik Indonesia di luar negeri

${ }^{7} / \mathrm{bid}$, hal. 44

c. Tidak memilik cukup biaya hidup selama berada di Indonesia

d. Memiliki penyakit menular, gangguan jiwa, atau hal-hal yang membahayakan kesehatan atau ketertiban umum. Terlibat tindak pidana internasional yang membahayakan keutuhan wilayah negara Indonesia atau termasuk dalam jaringan kegiatan prostitusi, perdagangan orang dan penyelundupan manusia.

Dalam mempekerjakan Tenaga kerja asing di Indonesia minimal terdapat 3 kelompok yang terlibat yaitu: pihak tenaga kerja asing, Perusahaan yang mempekerjakan Tenaga Kerja Asing dan pihak Pemerintah Indonesia. Artinya tenaga kerja asing yang ingin bekerja di Indonesia maupun pihak Dalam mempekerjakan Tenaga Kerja Asing di Indonesia, harus memenuhi apa yang telah ditetapkan oleh Perundang-undangan Republik Indonesia, baik bagi calon Pekerja maupun bagi Perusahaan yang akan mempekerjakan TKA.

Pada Undang-undang No. 13 Tahun 2003 tentang Ketenagakerjaan memberikan aturan- 
Media Komunikasi dan Informasi Hukum dan Masyarakat

aturan bagi Perusahaan maupun tenaga kerja asing yang hendak bekerja di Indonesia yang telah dirangkum sebagai berikut:

a. Pemberi kerja yang mempekerjakan TKA wajib mempunyai izin tertulis dari Menteri atau Pejabat yang berwenang;

b. TKA bekerja di Indonesia dalam suatu hubungan kerja, hanya boleh padajabatan tertentu dan waktu tertentu. Jabatan dan standar kompetensinya akan diatur didalam Keputusan Menteri Tenaga Kerja;

c. Pemberi Kerja harus memiliki rencana penggunaan TKA yang disahkan oleh Menteri atau Pejabat yang berwenang, didalamnya minimal memuat tentang:

(1) Alasan mempekerjakan TKA;

(2) Jabatan dan/atau kedudukan TKA dalam struktur organisasi Perusahaan yang bersangkutan;

(3) Jangka waktu TKA;

(4) Penunjukan Tenaga Kerja Indonesia (TKI) sebagai pendamping TKA tersebut.Pemberi Kerja wajib menunjuk Tenaga Kerja Indonesia pendamping, untuk alih teknologi dan keahlian dari TKA. Termasuk juga memberikan pendidikan dan pelatihan terhadap TKI tersebut. 8

Jadi ketentuan-ketentuan ini haruslah menjadi acuan baik terhadap calon TKA maupun perusahaan yang akan mempekerjakan TKA asing tersebut.

Penerimaan TKA di Indonesia digariskan untuk dapat memberikan keuntungan seluasluasnya terhadap bangsa dan negara Indonesia.

${ }^{8}$.Abdul Khakim, Dasar- Dasar Hukum Ketenagakerjaan, PT Citra Aditya Bakti, Bandung, hal. 24-25
Segala daya upaya dilakukan agar tidak ada celah yang merugikan bangsa dan negara Indonesia.

\section{B. Syarat-Syarat Tenaga Kerja Asing Di Indonesia.}

Setiap Warga Negara Asing yang mau bekerja di wilayah Negara Indonesia harus memenuhi syarat-syarat Ketenagakerjaan dan ketentuan keimigrasian sesuai dengan peraturan perundangan. ${ }^{9}$

TKA yang bekerja diwilayah Indonesia haruslah memenuhi syarat-syarat sebagai berikut:

a. Mempunyai pendidikan dan latar belakang pengalaman kerja, sekurang-kurangnya 5 (lima) tahun dan sesuai dengan jabatan yang akan ditempatinya;

b. TKA tersebut bersedia untuk membuat surat pernyataan untuk mengalihkan keahliannya kepada TKI pendamping;

c. TKA tersebut dapat berkomunikasi dalam bahasa Indonesia dan bersedia diuji kemampuannya;

d. TKA harus bekerja di Perusahaan yang mempunyai izin untuk dapat mempekerjakan TKA di Perusahaannya, disebut juga Izin Mempekerjakan Tenaga Kerja Asing (IMTA);

e. TKA harus melengkapi perizinan Keimigrasian, misalnya Paspor, Visa, izin masuk serta izin keimigrasian lainnya. ${ }^{10}$

TKA yang bekerja maupun Perusahaan yang mempekerjakan TKA di Perusahaannya haruslah berlandaskan peraturan yang telah digariskan oleh Pemerintah Indonesia. Penempatan TKA itu salah satu yang terpenting dimaksudkan agar dapat terjadi alih teknologi/

\footnotetext{
${ }^{9}$ Sihar Sihombing, Loc.cit.

${ }^{10}$. Sihar Sihombing, Loc cit.
} 
Media Komunikasi dan Informasi Hukum dan Masyarakat

alih ketrampilan dari TKA kepada TKI yang mendampingi. Jadi TKA itu haruslah orang yang berpendidikan, dengan telah berpengalaman bekerja dibidangnya dalam suatu perusahaan minimal 5 Tahun. Untuk itu maka calon TKA itu harus bersedia untuk membubuhkan tanda tangan pada surat pernyataan agar memberikan transfer keahliannya kepada TKI yang mendampinginya.

Berkaitan dengan jabatan-jabatan yang dilarang diduduki oleh TKA dalam suatu Perusahaan, Keputusan Menteri Tenaga Kerja dan Transmigrasi No. 40 Tahun 2012 menyebutkan beberapa jabatan yang dilarang sebagai berikut:

1. Direktur Personalia (Personel Director);

2. Manajer hubungan industrial (Industrial Relations Manager);

3. Manajer Personalia (Personnel Manager);

4. Supervisor Pengembangan

5. Personalia (Personnel Development Supervisor);

6. Supervisor Penempatan Personalia (Personnel Placement supervisor);

7. Supervisor Perekrutan Personalia (Personnel Recruitment Supervisor);

8. Supervisor pengembangan karier Pegawai (Employee Career Development Supervisor);

9. Penata Usaha Personalia (Personnel Declare Administrator);

10. Kepala Eksekutif Kantor (Cief executive Officer);

11. Akli Pengembangan Personalia (Personnel and Career Specialist);

12. Penasehat Karier (Career Advisor);

13. Pembimbing dan konseling jabatan (Job advisor and counseling);

14. Perantara Tenaga Kerja (Employee Mediator);
15. Petugas administrasi Pelatihan Pegawai (Job Training Administrator);

16. Pewawancara Pegawai (Job interviewer);

17. Analis Jabatan (Job Analyst);

18. Penyelenggara Keselamatan Kerja Pegawai (Occupatonal safety Specialist).

Larangan ini dilakukan, untuk membuat pembatasan agar TKA tidak bisa melakukan kesewenangan, yang bida berdampak negatif/ merugikan terhadap bangsa dan negara Indonesia, khusus kepada eksistensi Tenagakerja Indonesia itu sendiri.

Menurut PeraturanPemerintah (PP) No. 38 Tahun 2007 tentang Pengawasan penempatan TKA maka pembagian kewenangan dan pengawasan TKA adalah sebagai berikut:

a. Kewenangan Pemerintah meliputi:

(1) Pengesahan rencana TKA (RPTKA);

(2) Pengesahan RPTKA antarlintas Provinsi;

(3) Pengesahan RPTKA perubahan, misalnya perubahan jabatan, perubahan jumlah TKA, perubahan kewarganegaraan dll;

(4) Pemberian rekomendasi visa kerja danpenerbitan izin mempekerjakan TKA (IMTA);

(5) Penerbitan IMTA TKA (perpanjangan) yang lokasi kerjanya lebih dari satu wilayah Provinsi;

(6) Penyusunan jabatan terbuka dan tertutup bagi TKA;

(7) Pembinaan dan pengendalian penggunaan skala TKA nasional.

b. Kewenangan Pemerintah Provinsi mencakup:

(1) Pengesahan RPTKA perpanjangan yang tidak ada perubahan jabatan, 
Media Komunikasi dan Informasi Hukum dan Masyarakat

jumlah orang dan lokasi kerjanya dalam satu wilayah Provinsi;

(2) Penerbitan IMTA perpanjangan untu TKA yang lokasi kerjanya lintas kabupaten dalam satu provinsi;

(3) Pengawasan dan evaluasi penggunaan TKA yang lokasi kerjanya lintas kabupaten dalam satuProvinsi.

c. Kewenangan Pemerintah daerah kota/ Kabupaten adalah:

(1) Penerbitan IMTA perpanjangan untuk TKAyang lokasi kerjanya dalam wilayah Kabupaten/ Kota;

(2) Pengawasan dan evaluasi penggunaan TKA yang lokasi kerjanya dalam satu wilayah Kabupaten/ Kota.

Dari aturan-aturan yang berlaku terhadap TKA yang bekerja di Indonesia, maka TKA yang akan bekerja di Indonesia harus memenuhi ketentuan yang cukup ketat, supaya sejauh mungkin dihindarkan kerugian terhadap keberadaanTKI.

Dalam jurnal Kementerian Hukum dan HAM Republik Indonesia Direktorat Perundangundangan, dinyatakan:

Tujuan penggunaan TKA dilakukan secara selektif dengan tetap memprioritaskan TKI, oleh karenanya dalam mempekerjakan TKA, dilakukan melalui mekanisme dan prosedur yang ketat, terutama dengan cara mewajibkan bagi perusahaan atau korporasi yang menggunakan TKA asing bekerja di Indonesia dengan membuat Rencana Penggunaan Tenaga Kerja Asing (RPTKA) sebagai mana diatur dalam Peraturan Menteri Tenaga Kerja No.

\section{PER.12/MEN/III/2008 tentang tatacara penggunaan TKA. ${ }^{11}$}

Disisi lain Penggunaan TKA yang dipekerjakan di Indonesia mempunyai dampak positif seperti yang digambarkan dibawah ini :

Kehadiran TKA dapat dikatakan sebagai salah satu pembawa devisa bagi Negara, dimana adanya pembayaran kompensasi. Pembayaran kompensasiini dikecualikan pada pemberi kerjaTKA merupakan instansi pemerintah, Perwakilan Negara Asing, Badan- Badan Internasional, Lembaga social, Lembaga Keagamaan dan dalam jabatan- jabatan tertentu pada Lembaga Pendidikan. Besarnya danakompensasi untuk TKI di luar negeri adalah 15 dollar, sedangkan kompensasi untuk TKA di Indonesia sebesar 100 dollar. Kemudian dalam rangka pelaksanaan Transfer ofknowledge dari TKA kepada TKI kepada pemberi kerja diwajibkan untuk mengadakan pendidikan dan pelatihan bagi Tenaga Kerja Pendamping. ${ }^{12}$

Pengaturan terhadap TKA yang bekerja di Indonesia sebenarnya sudah cukup baik, namun yang penting mendapat perhatian bagaimana pelaksanaannya dilapangan. Pelaksanaan dilapangan, tentu banyak terkait dengan peran yang dilakukan oleh pejabat yang berkompeten. Pada prakteknya masih ada ditemui praktekpraktek yang menyalahi aturan-aturan tersebut.

Menurut Abdul Khakim bahwa pada fakta dilapangan, ternyata masih terjadi pelanggaran masih ada saja pelanggaran, dimana TKA mengurusi Kepersonaliaan. Memang mereka tahu hal itu dilarang oleh peraturan

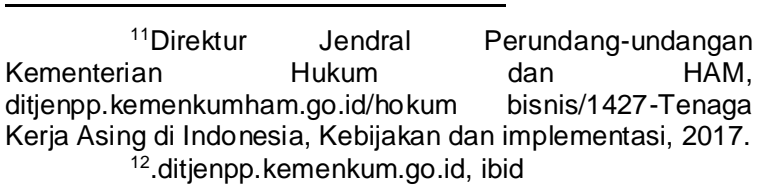


Media Komunikasi dan Informasi Hukum dan Masyarakat

perundangan Indonesia. Strateginya TKA tersebut secara formal memang mempunyai dokumen perizinan resmi, penempatannya bukan dibidang personalia, tapi secarapraktis TKA asing tersebut memegang kewenangan, dan selalu intervensi dibidang personalia, seperti: urusan rekruitmen, pembinaan tenaga kerja,pelatihan dan pengembangan, Pemutusan Hubungan Kerja (PHK) dll. ${ }^{13}$

Kemudian pada harian Haluan.com ditulis sebagai berikut:

Dalam realitas, banyak terdapat TKA nonteknis atau tanpa keahlian bekerja di Indonesia, bahkan diantara mereka merupakan TKA illegal, dengan kualifikasi rendah (buruh kasar), ini tentu mengkhawatirkan karena pekerja lokal dengan kualifikasi demikian sangat banyak tersedia di Indonesia. ${ }^{14}$

Dalam pelaksanaan pembangunan di Indonesia, dimana masih terdapat kebutuhan terhadap TKA khususnya yang mempunyai keahlian dibidang tertentu, maka sesuai dengan peraturan yang ada memang dimaksudkan TKI Pendamping mendapat ketrampilan yang berharga dalam rangka alih teknologi dan alih ketrampilan dibidang keahlian tertentu.

Pada prakteknya di lapangan berlandaskan aturan dan arah kebijakan yang jelas yang telah dirumuskan oleh Pemerintah terhadap keberadaan TKA memerlukan perjuangan dan pengawasan dalam mewujudkannya, agar tidak melenceng dari arah kebijakan yang telah dirumuskan Pemerintah Negara Republik Indonesia dibidang Ketenagakerjaan.

${ }^{13}$.Abdul Khakim, Dasar-Dasar Hukum Ketenagakerjaan Indonesia, PT Citra Aditya Bakti, Bandung, hal. 27

${ }^{14}$.https://harianhaluan.com/news/detail/60261/prol ematika Tenaga Kerja asing di Indonesia, 27 Sept 2017.

\section{Kesimpulan}

Jadi aturan-aturan yang mengatur dan arah kebijakan Pemerintah terhadap TKA di Indonesia, sudahcukup ketat dan selektif untuk melindungi kepentinganTKI sendiri agar tidak terdesak keberadaannya oleh TKA yang bekerja di Indonesia.

Dalam implementasi dilapangan, memang perlu komitmen, terutama dari pihak Pemerintah agar dapat menjalankan dan menerapkan berlakunya aturan-aturan dan pelaksanaan terhadap arah kebijakan tentang keberadaan TKA di Indonesia, sehingga tidak merugikan kepentingan tenaga kerja Indonesia itu sendiri dalam mencari lapangan pekerjaan di negerinya sendiri.

Jadi arah kebijakan Pemerintah terhadap keberadaan TKA di Indonesia adalah agar TKA yang bekerja di Indonesia merupakan TKA yang mempunyai keahlian tertentu yang dapat di turunkan kepada TKI pendamping, sehingga tenaga kerja ahli dari kalangan Pekerja Indonesia semakin lama semakin banyak. Pada suatu saat TKA tersebut dapat digantikan oleh TKI yang mempunyai keahlian dibidangnya.

\section{DAFTAR PUSTAKA}

\section{A. Buku}

Abdul Rachmad Budiono, Hukum Perburuhan di Indonesia, PT RajaGrafindo Persada, Jakarta, 2005

Abdul Khakim, Dasar- Dasar Hukum Ketenagakerjaan, PT Citra Aditya Bakti, Bandung, 2015.

Darwati dan Azis Budianto, Analisa Hukum Perjanjian Kerja waktu tertentu berdasarkan Undang- undang No. 13 Tahun 2003 tentang Ketenagakerjaan (Studi kasus Putusan PHI No. 46/PHI.G/2013/PN.Jkt.PST), Lex 
Media Komunikasi dan Informasi Hukum dan Masyarakat

Publica (Journal ilmu hukum Asosiasi

Pimpinan Perguruan Tinggi Hukum

Indonesia) Volume IV nomor 1, Penerbit

Asosiasi Pimpinan Perguruan Tinggi

Hukum Indonesia, Jakarta, 2017.

John Ruggie, Bagaimana menjalankan bisnis dengan menghormati hak asasi manusia, Global compact Network Indonesia, Lembaga Studi dan Advokasi Masyarakat (ELSAM), Jakarta, 2017.

Jazim Hamidi dan Charles Christian, Hukum Keimigrasian bagi orang asing di Indonesia, Sinar Grafika, Jakarta, 2015.

Sihar Sihombing, Hukum Keimigrasian dalam Hukum Indonesia, Nuansa Aulia, Jakarta, 2013.

\section{B. Perundang- undangan}

Undang-undang Republik Indonesia No.13 Tahun 2003 tentang Ketenagakerjaan, Lembaran Negara Republik Indonesia Tahun 2003 No. 39.

Undang-undang Republik Indonesia No. 6 Tahun 2011 tentang Keimigrasian, Lembaran Negara Republik Indonesia No.52 Tahun 2011

Peraturan Pemerintah Republik Indonesia No. 38 Tahun 2007 tentang Pengawasan penempatan Tenaga Kerja Asing di Indonesia.

Peraturan Menteri Hukum dan HAM Republik Indonesia No 24 Tahun 2016 tentang Prosedur Teknis permohonan danpemberian Visa Kunjungan dan Visa tinggal Terbatas Bagi WNA.

Keputusan Menteri Tenaga Kerja dan Transmigrasi No. 40 Tahun 2012 tentang jabatan- jabatan yang dilarang diduduki oleh TKAdi perusahaan di Indonesia.

\section{Internet}

Problematika Tenaga Kerja Asing di Indonesia, https://harian haluan.com/news/detail/60261/problem atika tenaga kerjaasing di Indonesia, 27 September 2016.

Tenaga Kerja Asing di Indonesia: kebijakan dan implementasi, ditjenpp.kemenkum.go.id/hokum bisnis/1427-tenaga kerja asing di Indonesia kebijakan dan implementasi.

Problematika data Tenaga kerja Asing, www.neraca.co.id/artcle/92876/proble $\mathrm{m}$ data Tenaga Kerja Asing, 13-112017 